TITLE:

\title{
Evolutionary changes of the importance of olfaction in cetaceans based on the olfactory marker protein gene.
}

\author{
$\operatorname{AUTHOR}(S)$ :
}

Kishida, Takushi; Thewissen, J G M

\section{CITATION:}

Kishida, Takushi ...[et al]. Evolutionary changes of the importance of olfaction in cetaceans based on the olfactory marker protein gene.. Gene 2012, 492(2): 349-353

\section{ISSUE DATE:}

2012-01-25

URL:

http://hdl.handle.net/2433/152383

\section{RIGHT:}

@ 2011 Elsevier B.V.; この論文は出版社版でありません。引用の際には 出版社版をご確認ご利用ください。; This is not the published version. Please cite only the published version. 


\section{Title}

Evolutionary changes of the importance of olfaction in cetaceans based on the olfactory marker protein gene

\section{Author names and affiliations}

Takushi Kishida $^{\mathrm{a}}$ (corresponding author) and J. G. M. Thewissen ${ }^{\mathrm{b}}$

${ }^{\text {a } D e p a r t m e n t ~ o f ~ Z o o l o g y, ~ G r a d u a t e ~ S c h o o l ~ o f ~ S c i e n c e, ~ K y o t o ~ U n i v e r s i t y ~}$

Kitashirakawa Oiwake-cho, Sakyo, Kyoto 606-8502, Japan.

tel: +8175753 4074, fax: +81757534114

e-mail: takushi@zoo.zool.kyoto-u.ac.jp

${ }^{\mathrm{b}}$ Department of Anatomy and Neurobiology, Northeast Ohio Medical University

4209 State Route 44, Rootstown, Ohio 44272, U. S. A.

e-mail: thewisse@neomed.edu 


\begin{abstract}
Odontocetes and mysticetes are two extant suborders of cetaceans. It is reported that the former have no sense of olfaction, while the latter can smell in air. To explain the ecological reason why mysticetes still retain their sense of smell, two hypotheses have been proposed - the echolocation-priority hypothesis, which assumes that the acquisition of echolocation causes the reduction of the importance of olfaction, and the filter-feeder hypothesis, which assumes that olfactory ability is important for filter-feeders to locate their prey because clouds of plankton give off a peculiar odor. The olfactory marker protein (OMP) is almost exclusively expressed in vertebrate olfactory receptor neurons, and is considered to play important roles in olfactory systems. In this study, full-length open reading frames of $O M P$ genes were identified in 6 cetacean species and we analyzed the nonsynonymous to synonymous substitution rate ratio based on the maximum likelihood method. The evolutionary changes of the selective pressures on $O M P$ genes did fit better to the filter-feeder hypothesis than to the echolocation-priority hypothesis. In addition, no pseudogenization mutations are found in all five odontocetes $O M P$ genes investigated in this study. It may suggest that OMP retain some function even in 'anosmic' odontocetes.
\end{abstract}

Keywords: aquatic adaptation; echolocation; Eocene whale; filter-feeder; OMP 


\section{Introduction}

Olfactory marker protein $(O M P)$ is a highly abundant small cytoplasmic protein encoded by an intronless $O M P$ gene (Margolis, 1972; Danciger et al., 1989). Expression of the OMP gene is highly restricted to mature olfactory chemosensory neurons, and is considered to play an important role in the olfactory signal-transduction cascade across vertebrate species (Margolis, 1980; Danciger et al., 1989; Reisert et al., 2007). Several studies reported that OMP-knockout mice show considerably reduced ability to respond to odor stimuli (Buiakova et al., 1996; Youngentob and Margolis, 1999; Youngentob et al., 2001), but the biochemical function of OMP remains largely elusive.

Amniotes that have undergone a transition from the terrestrial to aquatic environment generally have reduced olfactory capacity (Kishida and Hikida, 2010), and aquatic cetaceans are known to have reduced their sense of olfaction (Dehnhard, 2002). Olfactory receptor (OR) genes are highly reduced in cetacean genomes, especially in odontocetes (Kishida et al., 2007; McGowen et al., 2008; Hayden et al., 2010). Furthermore, modern odontocetes have no nervous system structures that mediate olfaction, i.e., no olfactory bulb or olfactory tract (Oelschläger and Oelschläger, 2008), suggesting that odontocetes have lost their sense of olfaction altogether. In contrast to odontocetes, mysticetes were shown in a recent study to have fully-equipped olfactory nervous system structures and histologically complex olfactory bulbs, indicating that they can smell in air (Thewissen et al., 2011). To explain the ecological reason why olfaction is present in mysticetes but absent in 
odontocetes, it has widely been considered that the acquisition of echolocation causes a reduction of the importance of olfaction (echolocation-priority hypothesis) (Cave, 1988; Hoch, 2000). However, mysticetes can smell in air, but not underwater (Thewissen et al., 2011), meaning that mysticete olfaction cannot be compensated for by the acquisition of echolocation, i.e., an underwater sonar system. Recently, another hypothesis has been proposed that olfaction is important for filter-feeders to locate their prey because clouds of plankton, especially krill, give off a peculiar odor on the surface of the sea (filter-feeder hypothesis) (Thewissen et al., 2011). Fig. 1 shows the evolutionary changes of the importance of olfaction each hypothesis predicts.

No cetacean $O M P$ genes have been reported to date. However, as described above, odontocetes have no tissues in which the $O M P$ gene is known to be expressed, and it is an interesting question whether the $O M P$ gene still has function in odontocetes or not. In addition, the evolutionary pathways of $O M P$ genes may reflect the evolutionary changes of the importance of olfaction. In this study, full-length open reading frames (ORFs) of OMP genes were identified in 6 cetacean species ( 5 odontocetes and a mysticete) and we analyzed the nonsynonymous to synonymous substitution rate ratio $\omega\left(d_{n} / d_{s}\right)$ based on the maximum likelihood (ML) method.

2. Materials and Methods 
2.1. Amplification and sequencing of whale $O M P$ genes

Muscle tissues of Baird's beaked whale Berardius bairdii and short-finned pilot whale Globicephala macrorhynchus were purchased from a fish market in Japan, and genomic DNA was extracted following the protocol described by Kishida et al. (2007). Genomic DNA samples of dwarf sperm whale Kogia sima, Dall's porpoise Phocoenoides dalli and minke whale Balaenoptera acutorostrata, which were prepared in Kishida et al. (2007), were used in this study. A set of primers, OMP_full_5 (5'-ACGGTGGAGGCGGCAGCAGCAA-3') and OMP_full_3 (5'-AGGGTAGCAGCAGGCAGCTGCCA-3'), was employed in PCR reactions to amplify the full-length sequences of the ORF of $O M P$ genes. Sequences of the PCR products were determined directly on an ABI3130 automated sequencer using BigDye terminator v3.1 (Applied Biosystems). The procedures we followed to design the OMP_full_5 and OMP_full_3 primers are provided as supplementary Methods. Minke whale, dwarf sperm whale, beaked whale, porpoise and pilot whale $O M P$ sequences are available in the DDBJ/EMBL/GenBank databases under the following accession numbers, respectively: AB626889, AB626890, AB626891, AB626892 and AB642168.

2.2. $O M P$ genes of bottlenose dolphin and terrestrial mammals

OMP gene sequences of human Homo sapiens (GenBank ID: BC069115), mouse Mus musculus (GenBank ID: U02557), dog Canis lupus (GenBank ID: XM_844636) and cow Bos taurus (GenBank ID: XM_865027) were retrieved from the GenBank database. The draft genome assembly 
of the bottlenose dolphin Tursiops truncatus was downloaded from the Ensembl genome browser release58 (http://www.ensembl.org/). The dolphin OMP gene sequence was searched for using the FASTA3.5 program (Pearson and Lipman, 1988) and the cow $O M P$ gene was used as a query. The positions of the initiation and termination codons were judged by comparison with the human, mouse, dog and cow $O M P$ gene sequences.

\subsection{Sequence analyses}

The $O M P$ genes thus obtained were aligned manually (Fig. 2). The nonsynonymous to synonymous substitution rate ratio $\omega$ provides an indication of the changes of selective pressures as follows: higher $\omega$ ratios indicate relaxation of purifying selection, and $\omega>1$ suggests positive selection (Yang, 2006). The CODEML program in the PAML4.4 package (Yang, 2007) was used to analyze changes of selective pressure based on widely-accepted phylogenetic relationships (human, mouse, (dog, (cow, (minke whale, (beaked whale, porpoise) )))). Several models shown in Table 1 were compared. In all models, the transition/transversion rates were not fixed and the F3×4 model was used for codon usage biases. Likelihood ratio tests were performed to compare between models, and the significance of differences was evaluated by calculating twice the log-likelihood difference assuming that it follows a $\chi^{2}$ distribution, with the number of degrees of freedom equal to the difference in the numbers of free parameters between models. The method of Zhang et al. (1997), in which the numbers of nonsynonymous and synonymous substitution sites in a particular branch were compared 
directly with those of nonsynonymous and synonymous sites which were not changed, was applied to examine the significant existence of positive/purifying selection. In this method, the numbers of nonsynonymous sites and substitutions, and synonymous sites and substitutions were estimated by the method of Nei and Gojobori (1986) based on the ancestral nucleotide sequences inferred by the Bayesian method (Yang et al., 1995). Numbers of nonsynonymous and synonymous sites were also estimated by the ML method (Goldman and Yang, 1994). We also modified the method of Zhang et al. (1997) to examine whether selective pressure on a particular branch can be considered as homogeneous in comparison with that on a compared branch. In this method, the numbers of nonsynonymous and synonymous substitutions were compared directly between these two branches (test of homogeneity of nonsynonymous/synonymous change ratios).

\section{Results}

The length of $O M P$ is highly conserved among mammalian species with the exception of three odontocetes (dwarf sperm whales, pilot whales and bottlenose dolphins). Sperm whales lack 4 amino acids (12 bp) located at the end of the first $\alpha$-helix, and delphinid whales (pilot whales and dolphins) lack 5 amino acids (15 bp) located at the third $\beta$-strand (Fig. 2). Sperm whale, pilot whale and dolphin $O M P$ sequences were excluded from ML analyses because these gaps reduce the computational regions from this short-length gene. The $\omega$ ratios, estimated based on the free-ratio 
model (allowing $\omega$ ratios to vary along different branches), are shown in Fig. 3(A). Interestingly, the $\omega$ ratios were much higher not only in the odontocete branches, but also in an ancestral branch named 'Eocene whale branch' [a tree branch which represents the lineage that includes the common ancestors of mysticetes and odontocetes. Most of this branch has been in the Eocene Epoch (Fig. 1)], in comparison with those in the mysticete branch and the terrestrial mammal branches. This trend is also apparent even if sperm whale, pilot whale and dolphin $O M P$ sequences are added to the analysis (supplementary Fig. S1). To test whether $\omega$ ratios in these branches are significantly higher compared to those in other branches or not, several models were compared, as shown in Table 1 and Table 2. The one-ratio model (model 2; assuming that all branches have evolved under the same $\omega$ ratio) was rejected when compared to the free-ratio model (model 1), indicating that these mammalian $O M P$ genes have not been subject to similar selective pressures. Four two-ratio models (models 3, 4, 5 and 6; allowing two $\omega$ ratios) showed significantly better fit to the data than did the one-ratio model, suggesting that purifying selection on $O M P$ genes became relaxed around the evolutionary appearance of the cetacean lineages. Two three-ratio models (models 7 and 8; allowing three $\omega$ ratios) showed significantly better fit to the data than did the three two-ratio models (models 3, 4 and 5), while model 6 was as well fitted as the three-ratio models and the free-ratio model. Especially, comparison between model 4 and model 7 suggested that the pressure of purifying selection on the $O M P$ gene had been relaxed in the Eocene whale branch, and comparison between model 3 and model 8 suggested that the $O M P$ gene has been under strong purifying selection in the mysticete 
branch. The test of homogeneity of nonsynonymous/synonymous change ratios also shows that there has been stronger pressure of purifying selection in the mysticete branch compared to the odontocete branches and the Eocene whale branch (Fig. 3(B)). These results revealed that $\omega$ ratios were significantly higher in the Eocene whale branch and the odontocete branches compared to the mysticete branch and other mammalian branches.

\section{Discussion}

\subsection{Evolutionary changes of the importance of olfaction in cetaceans}

Selective pressures of purifying selection on the $O M P$ genes were strong in the mysticete branch and the terrestrial mammal branches but relaxed in the odontocete branches, in agreement with the presence of olfaction in the former, but loss in the latter. Selective pressure of purifying selection on the $O M P$ gene in the mysticete branch was significantly stronger compared to that in the Eocene whale branch, but there were no significant differences between that in the odontocete branch and that in the Eocene whale branch. Considering these results together, we conclude that the evolutionary changes of the selective pressures on $O M P$ genes showed better fit to the filter-feeder hypothesis than to the echolocation-priority hypothesis. Our data suggest that the difference of the olfactory abilities between mysticetes and odontocetes cannot be explained by the echolocation-priority hypothesis, or at least by the echolocation-priority hypothesis alone, and that 
the change of feeding behavior in the mystecete lineage is a possible factor to explain it.

Olfaction is mediated by cranial nerve I. The fibers of this nerve pass through the cribriform plate of the ethmoid bone, and the presence/absence of cribriform plate can be an indicator for the presence/absence of olfaction (Philström, 2008). The presence of a cribriform plate, which is absent in the modern odontocetes, has been documented in Eocene whales including fully aquatic basilosaurids (Uhen, 2004). It means that, although the pressure of purifying selection on the $O M P$ gene in the Eocene whale branch had been relaxed, the ancestral cetaceans retained a sense of smell. However, there are several lines of evidence reported that cetaceans had reduced their sense of smell gradually during the Eocene Epoch. For example, the anterior palatine foramen has been documented in the amphibious pakicetids (Thewissen and Hussain, 1998), but it was absent in the amphibious remingtonocetids (Thewissen and Bajpai, 2009; Bajpai et al., 2011) and the fully aquatic basilosaurids (Uhen, 2004). We speculate that, in Eocene evolution of cetaceans, olfaction had not been lost from the aquatic ancestors completely, but it may have decreased in importance.

\subsection{Odontocete $O M P$ genes}

Generally, genes are prone to pseudogenization if they have no function in their organisms. For example, the TRPC2 genes, which are essential to vomeronasal olfaction, have become pseudogenes in cetacean species (Yu et al., 2010) because extant cetaceans have lost vomeronasal organs (Philström, 2008), and the tooth gene enamelysin was pseudogenized in the tooth-less mysticetes 
(Meredith et al., 2011). However, no pseudogenization mutations (frameshift mutations and/or nonsense mutations) are found in any odontocete $O M P$ genes investigated in this study. The dwarf sperm whale has lost $12 \mathrm{bp}$ and the delphinid whales have lost $15 \mathrm{bp}$, but both of these numbers are multiples of three and therefore these losses do not cause frameshifts. Are $O M P$ genes still functional in odontocetes? There is no significant evidence of positive or purifying selection in any branches among the odontocete branches and the Eocene whale branch based on the method of Zhang et al. (1997) (supplementary Table S1), meaning that we cannot answer this question yet. Baker et al. (1989) reported that though the $O M P$ is almost exclusively expressed in mature olfactory receptor neurons, it is also expressed in small groups of neurons in the central nervous system. It may be possible that odontocete $O M P$ is required in these areas. Further studies are required to answer this question, and to reveal the biochemical function of $O M P$.

\section{Acknowledgements}

We are grateful to Y. Shintaku and T. Hikida for valuable comments; E. Kawaguchi and E. Nakajima for technical supports. This work was supported by Global COE program (A06) of Kyoto University, and by MEXT KAKENHI (22770082) to TK.

\section{References}

Bajpai, S., Thewissen, J.G.M., Conley, R.W., 2011. Cranial anatomy of middle Eocene 
Remingtonocetus (Cetacea, Mammalia) from Kutch, India. J. Paleontol. 85, 703-718.

Baker, H., Grillo, M., Margolis, F.L., 1989. Biochemical and immunocytochemical characterization of olfactory marker protein in the rodent central nervous system. J. Comp. Neurol. 285, 246-261.

Buiakova, O.I., Baker, H., Scott, J.W., Farbman, A., Kream, R., Grillo, M., Franzen, L., Richman, M., Davis, L.M., Abbondanzo, S., Stewart, C.L., Margolis, F.L., 1996. Olfactory marker protein (OMP) gene deletion causes altered physiological activity of olfactory sensory neurons. Proc. Natl. Acad.

Sci. U. S. A. 93, 9858-9863.

Cave, A.J.E., 1988. Note on olfactory activity in mysticetes. J. Zool. 214, 307-311.

Danciger, E., Mettling, C., Vidal, M., Morris, R., Margolis, F., 1989. Olfactory marker protein gene:

Its structure and olfactory neuron-specific expression in transgenic mice. Proc. Natl. Acad. Sci. U. S. A. $86,8565-8569$.

Dehnhardt, G., 2002. Sensory systems, in: Hoelzel, R., (Ed.), Marine mammal biology. Blackwell Publishing Ltd., New York, pp. 116-141.

Goldman, N., Yang, Z., 1994. A codon-based model of nucleotide substitution for protein-coding DNA sequences. Mol. Biol. Evol. 11, 725-736.

Hayden, S., Bekaert, M., Crider, T.A., Mariani, S., Murphy, W.J., Teeling, E.C., 2010. Ecological adaptation determines functional mammalian olfactory subgenomes. Genome Res. 20, 1-9.

Hoch, E., 2000. Olfaction in whales: evidence from a young odontocete of the late Oligocene north sea. Historical Biol. 14, 67-89. 
Kishida, T., Kubota, S., Shirayama, Y., Fukami, H., 2007. The olfactory receptor gene repertoires in secondary-adapted marine vertebrates: evidence for reduction of the functional proportions in cetaceans. Biol. Lett. 3, 428-430.

Kishida, T., Hikida, T., 2010. Degeneration patterns of the olfactory receptor genes in sea snakes. J. Evol. Biol. 23, 302-310.

Margolis, F.L., 1972. A brain protein unique to the olfactory bulb. Proc. Natl. Acad. Sci. U. S. A. 69 , $1221-1224$

Margolis, F.L., 1980. A marker protein for the olfactory chemoreceptor neuron, in: Bradshaw, R.A., Schneider, D.M. (Eds.), Proteins of the Nervous System. Raven Press, New York, pp. 59-84.

McGowen, M.R., Clark, C., Gatesy, J., 2008. The vestigial olfactory receptor subgenome of odontocete whales: phylogenetic congruence between gene-tree reconstruction and supermatrix methods. Syst. Biol. 57, 574-590.

Meredith, R.W., Gatesy, J., Cheng, J., Springer, M.S., 2011. Pseudogenization of the tooth gene enamelysin (MMP20) in the common ancestor of extant baleen whales. Proc. Biol. Sci. 278, 993-1002.

Nei, M., Gojobori, T., 1986. Simple methods for estimating the numbers of synonymous and nonsynonymous nucleotide substitutions. Mol. Biol. Evol. 3, 418-426.

Oelschläger, H.H.A., Oelschläger, J.S., 2008. Brain, in: Perrin, W.F., Würsig, B., Thewissen, J.G.M. (Eds.), Encyclopedia of marine mammals, second ed. Elsevier, Amsterdam, pp. 134-149. 
Pearson, W.R., Lipman, D.J., 1988. Improved tools for biological sequence comparison. Proc. Natl. Acad. Sci. U. S. A. 85, 2444-2448.

Pihlström, H., 2008. Comparative anatomy and physiology of chemical senses in aquatic mammals, in: Thewissen, J.G.M., Nummela, S. (Eds.), Sensory evolution on the threshold: adaptation in secondarily aquatic vertebrates. University of California Press, Berkeley, pp. 95-111.

Reisert, J., Yau, K.W., Margolis, F.L., 2007. Olfactory marker protein modulates the cAMP kinetics of the odour-induced response in cilia of mouse olfactory receptor neurons. J. Physiol. 585, 731-740.

Smith, P.C., Firestein, S., Hunt, J.F., 2002. The crystal structure of the olfactory marker protein at 2.3A resolution. J. Mol. Biol. 319, 807-821.

Thewissen, J.G.M., Hussain, S.T., 1998. Systematic review of Pakicetidae, early and middle Eocene Cetacea (Mammalia) from Pakistan and India. Bulletin of the Carnegie Museum of Natural History $34,220-238$.

Thewissen, J.G.M., Bajpai, S., 2009. New skeletal material of Andrewsiphius and Kutchicetus, two Eocene cetaceans from India. J. Paleontol. 83, 635-663.

Thewissen, J.G.M., George, J., Rosa, C., Kishida, T., 2011. Olfaction and brain size in the bowhead whale (Balaena mysticetus). Mar. Mamm. Sci. 27, 282-294.

Uhen, M.D., 2004. Form, function, and anatomy of Dorudon atrox (Mammalia, Cetacea): an archaeocete from the middle to late Eocene of Egypt. University of Michigan Papers on 
Paleontology 34, 1-222.

Uhen, M.D., 2007. Evolution of marine mammals: back to the sea after 300 million years. Anat. Rec. $290,514-522$

Yang, Z., Kumar, S., Nei, M., 1995. A new method of inference of ancestral nucleotide and amino acid sequences. Genetics 141, 1641-1650.

Yang, Z., 2006. Computational molecular evolution. Oxford University Press, Oxford.

Yang, Z., 2007. PAML 4: phylogenetic analysis by maximum likelihood. Mol. Biol. Evol. 24, $1586-1591$.

Youngentob, S.L., Margolis, F.L., 1999. OMP gene deletion causes an elevation in behavioral threshold sensitivity. NeuroReport 10, 15-19.

Youngentob, S.L., Margolis, F.L., Youngentob, L.M., 2001. OMP gene deletion results in an alternation in odorant quality perception. Behav. Neurosci. 115, 626-631.

Yu, L., Jin, W., Wang, J., Zhang, X., Chen, M., Zhu, Z., Lee, H., Lee, M., Zhang, Y., 2010. Characterization of TRPC2, an essential genetic component of VNS chemoreception, provides insights into the evolution of pheromonal olfaction in secondary-adapted marine mammals. Mol. Biol. Evol. 27, 1467-1477.

Zhang, J., Kumar, S., Nei, M., 1997. Small-sample tests of episodic adaptive evolution: a case study of primate lysozymes. Mol. Biol. Evol. 14, 1335-1338. 


\section{Figure 1}
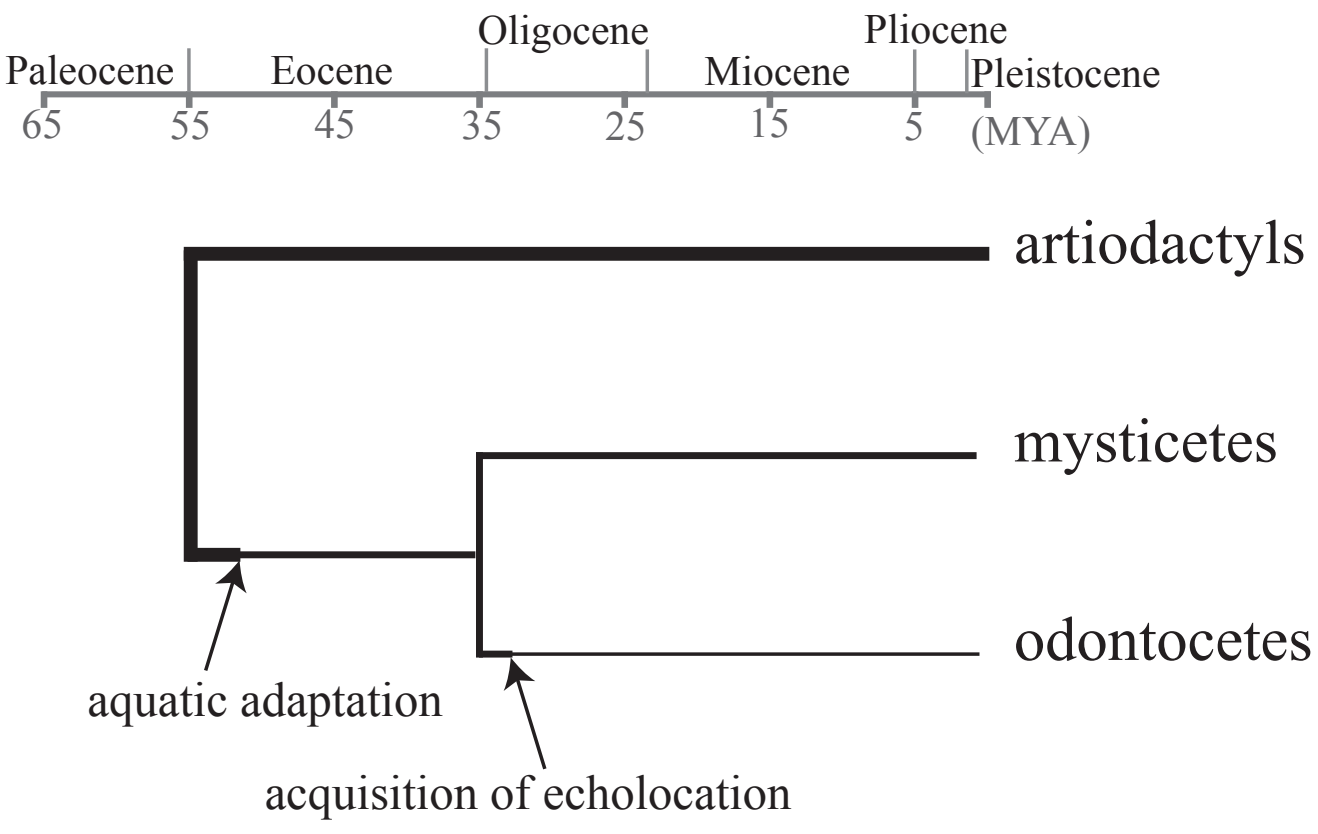

A. Echolocation-priority hypothesis

artiodactyls

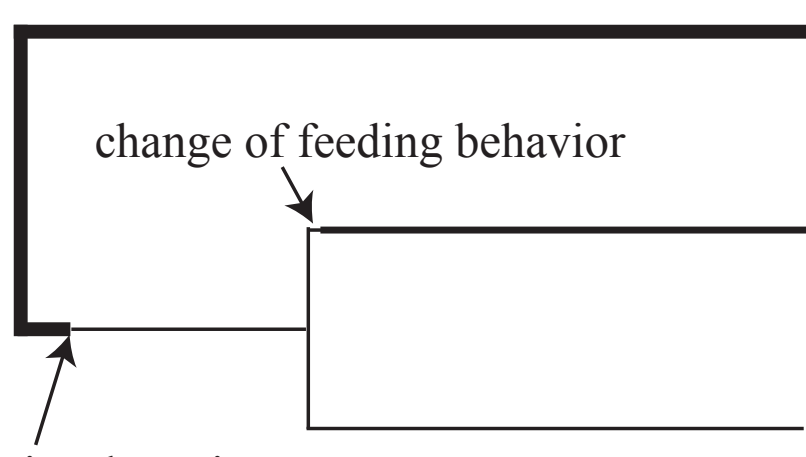

mysticetes

aquatic adaptation

odontocetes

B. Filter-feeder hypothesis 
human
mouse

mouse
dog

cow
minke whale

minke whale
dwarf sperm whal

beaked whale
pilot whale

pilot whale

Dall's porpoise

$+\mathrm{H}_{3} \mathrm{~N}$

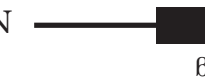

MAEDRPQQPQLDMPLVLDQGLTRQMRLRVESLKQRGEKRQDGEKLLQPAESVYRLNFTQQQRLQFERWNVVLDKPGKVTITGTSONWTPDLTNLMTRQLIDPTAIFWRKEDSDDAIDWNEADALEFGERLSDLAKIRKVMYYFLVTFGEGVEPANLKASVVFNQL. MAEDGPQKQQLEMPLVLDQDLTQQMRLRVESLKQRGEKKQDGEKLIRPAESVYRLDFIQQQKLQFDHWNVVLDKPGKVTITTGTSQNWTPDLTNLMTRQLLDPAAI FWRKEDSDAMDWNEADALEFGERLSDLAKIRKVMYFLITFGEGVEPANLKASVVFNQL. MAEDGPKQPQLSMPLVLDPDLTKQMRLRVESLKQRGEKRQDGEKLLRPAEAVYRLDFVQQQKLQFERWDVELDKPGKVTI ITGTSQNWTPDLTNLMTRQLLDDPAAI FWRKEDAEAMDWNEADALEFGERLSDLAKI IRKVMYFLITFGEGLEPANLKASVVFNQI . MAEDEPKPSQLSM LVDRDLTKQMRLRMEST QRGQKRQDGEKLLRPSESVYRIDF IQQHRLQFERWDVVLDQPGKVITTGTSQNWTPDLTNLMTRQLDPAAIFWRKEDSEAMDWNEADALEFGERLSDLAKIRKVMYFLITFSEGLEPANLKASVVFNQL . MAEDEPK QLDMPLVLDEDLTKQMRLRVESLKRRGRKRQDGEKLLQPAESVYRIDF IQQQRLQFERWDVVDKPGKVTITGTSQIWTPDLTNLMTRQLLDPAAIFWRKEDSEAMDWNEADALEFGERLSELAKIRKVMYFLISFSEGVEPANLKASVVFSQI. M MAEDEPKPTQLDTPLVLGEDLTKQMRLRVESLKQRGGKRQDGEKLPPPAESVYHIDF IQQQRL-----NVMLDKPGKVTITGTSQIWMPDLTNLMTRQLIDRAAI FWRKEDSEAMDWNEADALEFGERLSELAKIRKVMYFLITFSEGIEPANLKASVVFSQI.

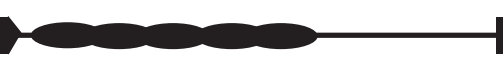

$\alpha^{-1}$
6-2
B-3
B-4
6-5 $a-2$
B-7 
Figure 3

A

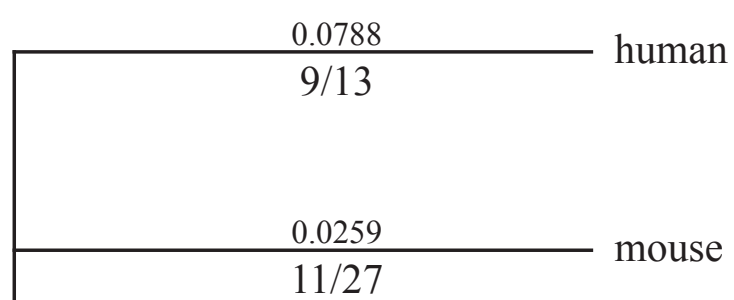

$11 / 27$
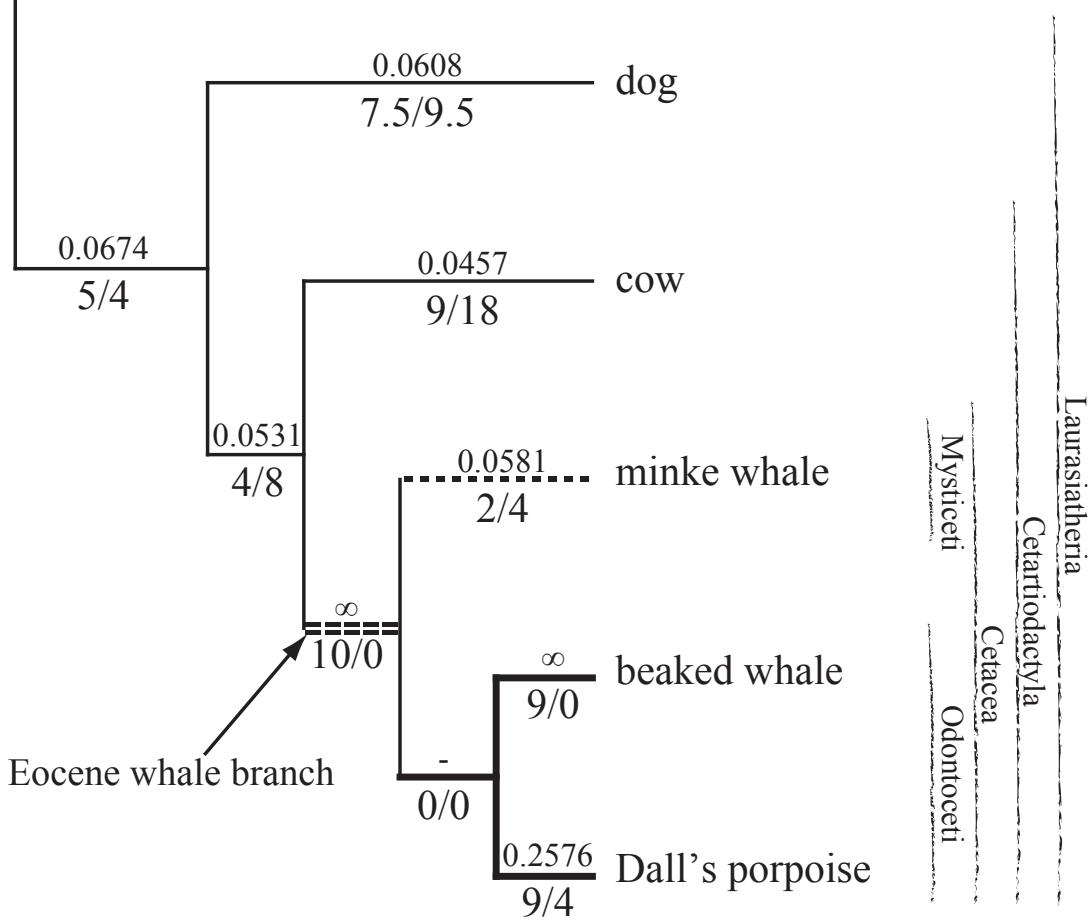

B

Test of homogeneity of nonsynonymous/synonymous change ratios

\begin{tabular}{lrrr}
\hline & \multicolumn{2}{c}{ numbers of substitutions } & \multirow{2}{*}{ P value } \\
\hline monsynonymous & synonymous & \\
odontocete branches & 2 & 4 & \\
& 18 & 4 & $0.038^{*}$ \\
mysticete branch & 2 & & \\
Eocene whale branch & 10 & 4 & \\
& & 0 & $0.008^{* *}$ \\
odontocete branches & 18 & & \\
Eocene whale branch & 10 & 4 & \\
\hline
\end{tabular}

* significant $(P<0.05)$

** extremely significant $(P<0.01)$ 
Figure 1.

The predicted evolutionary changes of the importance of olfaction based on the echolocation-priority hypothesis (A) / the filter-feeder hypothesis (B). Thinner branches indicate less importance of olfaction. Geological scale bar is provided above, and the periods of the evolutionary events follow Uhen (2007). The echolocation-priority hypothesis predicts that the importance of olfaction has been reduced in the odontocete branch since the acquisition of echolocation, while olfaction is as important for mysticetes as for their aquatic ancestors. On the other hand, the filter-feeder hypothesis predicts that the olfaction is as useless for odontocetes as for their aquatic ancestors, while the importance of olfaction has been increased in the mysticete branch since they have become filter-feeders.

Figure 2.

Aligned amino acid sequences of $O M P$ genes of 10 mammals investigated in this study. Gap sites are represented by “-”, and termination sites are represented by ".”. The secondary structure of OMP follows Smith et al. (2002), and the positions of two a-helices, 8 B-strands and an EphB2-receptor-like loop are shown at the bottom of the alignment.

Figure 3.

A. The nonsynonymous to synonymous rate ratios $(\omega)$ in each branch, calculated based on the free-ratio model. The estimated numbers of nonsynonymous substitutions / synonymous 
substitutions, calculated by the method of Nei and Gojobori (1986), are also shown under each branch based on the ancestral nucleotide sequences inferred by the Bayesian method (Yang et al., 1995). Bold lines, a single dashed line and a double dashed line represent the odontocete branches, the mysticete branch and a branch named “Eocene whale branch”, respectively.

B. Tests of homogeneity of nonsynonymous/synonymous change ratios. $P$-values were calculated using Fisher's exact test. 
Table 1. Log likelihood values, $\omega$ ratios and parameters estimated using different models

\begin{tabular}{|c|c|c|c|c|c|c|}
\hline model & $p$ & $\kappa$ & $l$ & $\omega 0$ & $\omega 1$ & $\omega 2$ \\
\hline 1. free-ratio & 23 & 4.08 & -1352.644 & & & \\
\hline 2. one-ratio & 13 & 3.88 & -1371.036 & 0.0804 & & \\
\hline 3. two-ratio $\left(\omega 1\right.$ : cetaceans ${ }^{\mathrm{a}}, \omega 0$ : other branches $)$ & 14 & 4.06 & -1359.409 & 0.0482 & 0.3844 & \\
\hline 4. two-ratio ( $\omega 1$ : odontocetes, $\omega 0$ : other branches) & 14 & 4.00 & -1362.136 & 0.0593 & 0.5314 & \\
\hline 5. two-ratio ( $\omega 1$ : Eocene whale, $\omega 0$ : other branches) & 14 & 3.95 & -1367.058 & 0.0695 & $\infty$ & \\
\hline 6. two-ratio ( $\omega 1$ : odontocetes + Eocene whale, $\omega 0$ : other branches) & 14 & 4.05 & -1356.981 & 0.0489 & 0.6413 & \\
\hline 7. three-ratio ( $\omega 2$ : Eocene whale, $\omega 1$ : odontocetes, $\omega 0$ : other branches) & 15 & 4.07 & -1356.431 & 0.0482 & 0.5321 & $\infty$ \\
\hline 8. three-ratio ( $\omega 2$ : mysticete, $\omega 1$ : odontocetes + Eocene whale, $\omega 0$ : other branches) & 15 & 4.06 & -1356.937 & 0.0483 & 0.6411 & 0.0637 \\
\hline
\end{tabular}

${ }^{a}$ cetaceans $=$ odontocete branches + mysticete branch + Eocene whale branch

$p$; number of parameters.

$\kappa ;$ transition/transversion rate ratio.

$l ; \log$ likelihood value. 
Table 2. Likelihood ratio tests between different models

\begin{tabular}{ccccc}
\hline tested model $^{\mathrm{a}}$ & compared model $^{\mathrm{a}}$ & $2 \Delta l$ & d.f. & $P$ value \\
\hline 2 & 1 & 36.784 & 10 & $6.2 \times 10^{-5 * *}$ \\
2 & 3 & 23.254 & 1 & $1.4 \times 10^{-6} * *$ \\
2 & 4 & 17.800 & 1 & $2.5 \times 10^{-5} * *$ \\
2 & 5 & 7.956 & 1 & $0.0048^{* *}$ \\
2 & 6 & 28.110 & 1 & $1.1 \times 10^{-7} * *$ \\
3 & 7 & 5.956 & 1 & $0.015^{*}$ \\
4 & 7 & 11.410 & 1 & $7.3 \times 10^{-4} *$ \\
5 & 7 & 21.254 & 1 & $4.0 \times 10^{-6} * *$ \\
6 & 7 & 1.100 & 1 & 0.29 \\
3 & 8 & 4.944 & 1 & $0.026^{*}$ \\
4 & 8 & 10.398 & 1 & $0.0013^{* *}$ \\
5 & 8 & 20.242 & 1 & $6.8 \times 10^{-6} * *$ \\
6 & 8 & 0.088 & 1 & 0.77 \\
6 & 1 & 8.674 & 9 & 0.47 \\
\hline
\end{tabular}

${ }^{a}$ model numbers follow those in Table 1

* significant $(P<0.05)$

** extremely significant $(P<0.01)$ 